\title{
Information Communication Technology (ICT) usage in the South African Construction Professional Practice: Lessons Learnt
}

\author{
Aigbavboa, C.O., *Thwala W.D., Lesito, K.P. \\ University of Johannesburg, Doornfontein Campus, Johannesburg, South Africa \\ *didibhukut@uj.ac.za
}

\begin{abstract}
This paper examines the impact of ICT in professional practice in the South African construction industry. This is with the view that ICT utilization in professional practice has the potential to facilitate better decision-making ability and savings in operating costs, amongst others. The data for the study was derived from both primary and secondary sources. The primary data was obtained through the survey method, while the secondary data was obtained from the review of literature. The primary data for the study was collected through a structured questionnaire survey distributed to a sample of 37 professionals in the construction industry. The results revealed that architectural, engineering and quantity surveying functions have been largely computerised. However, data and document management is still done through the traditional way of manual filing. Therefore, because construction industry professionals are a rich source of information about ICT and its improvement within the industry, the study provide valuable insight into the current usage of ICT in construction professional practise firms, which thus reveals the level of ICT adaptation in South African CI. Hence, this thus shows that ICT surveys can be used to determine the number of users of these systems, identify the core impacts ICT has had on day to day activities.
\end{abstract}

Keywords: Information Communication Technology, Construction Industry, Proffesional Practice

\section{Introduction}

The importance of communication within the construction industry cannot be over emphasized as this is one key aspect that brings all professionals in the industry together, towards the practice of construction and its related works. Since professional needs to prove themselves on the job daily, the need for communication finds relevance in every professional endeavour. Due to the hierarchal and fragmented nature of construction works, a close coordination among a large number of specialized but interdependent organizations and individuals to achieve the cost, time and quality of goals of a construction project is required (Toole, 2003). Like any project exchange of information is always present between all participants, with respect to the construction industry and its associated activities which require heavy exchange of data and information between project participants on a daily basis, the need for a medium and systems which will help facilitates this process is great desired. For instance, Rivard et al., (2004) posit that information sharing plays two vital roles in all construction projects, which are the specification of the resulting product (design information) and the initiation and control of the activities required for constructing the facility (management information). These two identified critical roles of information in a construction project have a starting point, that is, they are distributed to the particular project participants - the design team normally referred to as the Professional team who in this context act as professional advisers to the client. These are the main producers and disseminators of the information sent out regarding the project. Sadly enough, a majority of construction information exchange are still based on traditional means of communication such as face-to-face meetings and the exchange of paper documents (Working Drawings from the Engineer or Architect), specifications and site instructions. This slow pace of adapting to change, is one of the reasons while the construction industry has for many years suffered from the difficult-to-access, out-of-date and incomplete information (Shoesmith, 1995).

In order to manage a construction project properly accurate and up-to-date information is required at all times so that no delays and failures can be encountered. Hence, all project participants must be up to speed with the changes that are happening within the project. Unlike other industries, the need to increase the efficiency of information management by exchanging massive volumes of information at high speeds and at relatively low costs has long been recognized and fully embraced. This study is therefore an attempt to evaluate the impact of ICT on construction professional consultants in the South Africa 
construction industry. Against this background, this paper presents an empirical analysis of the impact theadapation and use of ICT has had on their professional responsibilities. To this end, the specific objectives of the study are to: to identify the factors that determine the use of ICT by construction consultants in South Africa;identify the constraints to the use of ICT by the consultants; and to assess the benefits of ICT usage to the consultants. The next sections of the articleoutlines the current use of ICT in construction professional practice and by the construction professional. This is followed a description of the methodology adopted for the study in order to meet the above research objectives. This is followed by the analysis and discussion of the research results, before conclusions are drawn and recommendations made.

\section{Construction Professional Practice}

The Construction Industry (CI) in South Africa as in most countries, is made up of different sectors such as various client groups (private, corporate and the government), the provincial and municipal departments, private organisations, individuals, developers, contractors, suppliers, manufacturers and professionals (such as, architects, quantity surveyors, and engineers incorporating civil, structural, mechanical and electrical amongst others). Besides, there are supporting legislative regulatory bodies whose function is to ensure that all professional in the CI adhere to the industry standards and ethical codes and ensure that the clients and the general public is protected against and potential damage through the various building byelaws. This is because a profession is an occupation that requires both advanced study and mastery of a specialized body of knowledge and undertaken to promote, ensure or safeguard some matter that significantly affects others' well-being (Vee and Skitmore, 2003).A common future of the CI is the fragmentation of the different professionals and sectors in the industry (Segalas et al., 2010). Hence, each professional is bound, based on their training, expertise and the CI fragmentation of job to exercise their own skills and judgement thus contributing to a network of other professional in order to make good on the CI project demands.In general, professional practices are largely created and sustained by the continued interest, expectations and demand of the public and private clients. Moreover, professionalism is imperative of certain core values; competencies, responsibility and willingness to serve (Chalkey, 1990) public interest through various means and avenues that make information and other requirements easier to dissemination everybody concerned. This is because the faster transmission and dissemination of information and services determines the continuous demand, relevance and continued existence of any profession practice. This installs confidence, competence, professionalism as well as the pride and respect for the quality performance of services rendered from the clients and other professional alike.

The systemic complexity of the construction industry with respect to project performance is not only targeted at meeting clients' demands through the dynamism of technical competencies and innovative skills but the adaptation of the relevant tools (such as ICT tools) will go a long way to ensure that project delays are avoid and the client is satisfied with the service rendered. Construction professional service providers within the South Africa built environment represent one of the major pools of skilled technical resources in the country that are used to ensure that technical designs, engineering and construction works are of good quality and are cost-effective and on time. Good quality engineering, infrastructure development and prompt project delivery are essential to South African's growth and development and hence these skilled resources also play an important role in ensuring that the country remains technically competitive from a global perspective (Construction Industry Development Board, 2005).Hence, the adaptations of the necessary tools as such as ICT will enable the professional practice firms to delivery with efficiency there services in the construction industry and thus help to create and maintain a balance in the delivery of their expertise to clients and ensure there continued attractiveness and development of these professions on the one hand, and ensuring competitiveness on the other hand.CI professional practice in South Africa has become increasingly dependent on computers. Despite the adaptation and usage, professionals firms should be mindful of the difficulties that can exist and exercise due diligence during usage (The Association of Professional Engineers and Geoscientists of Alberta, 2013). This is because computer software development is based upon many assumptions, judgments and interpretations that can lead to subtle limitations in computed results. Hence, professional practice and its professional employees should carefully verify that the results obtained from computer software, or store through the use of software programs are accurate and acceptable. Where appropriate, new software releases should be verified against a standard and certified for general use.

All computer programs, and especially those generated internally, should be documented thoroughly as to assumptions, methods of operation and limitations. Appropriate file back-up procedures should be 
implemented. The firm should also ensure that all computer users are appropriately trained and have developed sufficient skill to use the equipment and software effectively (The Association of Professional Engineers and Geoscientists of Alberta, 2013). The holistic adaptation of ICT tools in the South African CI professional practice firms will enable the ability and competence of the firms and its staff to meet its professional obligations. This is because the accurate and well-documentation of records of communications and prompt response to clients' needs and other professional request are important to any professional practice. Miscommunication can be costly, and in the worst case, place disadvantage the firm in having a fair share of the market. Hence, through the adaptation of ICT, professional practice firms would have adopted a better and efficient method of handling, documenting and sharing of communications and other valuable information. ICT would also enable the firms to keep accurate and complete records for all projects until the professional liability period expires. These records include documentation of the methodology used in performing professional work, drawings, design calculations, shop drawings, reports and other communication documents.

The current use of ICT in Construction professional practice:The construction industry is currently experiencing a paradigm shift from traditional paper-based information sharing to digitally based information exchange, which other industries such as aircraft, manufacturing and banking have since adopted and benefited from long ago (Rivard et al., 2004). This shift has been aided to a large extent by the drastic reduction in computer hardware and software prices and the increased in efficiency, usefulness and popularity of computers over the last few years and most especially in South Africa. However, in South African, a large chuck of its software are imported and the cost of internet data bundle is one of the highest in the world. However, with the growing trend of more and more computers being connected by the aid on Internet to form the worldwide web, firms located on different cities, provinces, locations and even countries are readily able to exchange information. According to Ruikar, Anumba \& Carrillo, (2005)ICT can greatly impact the traditional processes of professional organizations in construction and result in change in organizational processes, working methods and culture. This will builds a much more sound and stable collaborative working environment within the domains of the construction industry similar to other industries that have benefited from the total embrance of ICT. In this context, it therefore means that some benefits of ICT are critical to the performance of professional consultants. Prime amonsgt these include the reduction of time for data processing and communicating information within other professionals, and improvement in communications for effective decisionmaking and coordination among construction/project participants (Peansupap\& Walker, 2005), which at the end enhance construction productivity (Liston, Fischer \& Kunz, 2000). For this to be possible, the use of Internet-based tools of ICT which allows communication between remote and deserted user within the construction industry such as in remote areas which enables the sharing of files, comment on changes, propose changes, requests for information, clarity on information received, discuss issues being faced with regards to the information given to the professional consultants is highly necessary.

While a lot of ICT (particularly hardware) are commonly required in architectural engineering and quantity surveying practices, others (software related) are profession-specific (Oladapo, 2006). The common types of software's used in almost all profesional practise firms include Microsoft Word, Microsoft excel, AutoCAD and Internet related software (Goh, 2005). The areas of thorough application with the use of ICT as a tool to the relevant professions is mainly based on administration, communication, marketing, desktop publishing, presentation and project management, design, project monitoring amongst others. For instance, architects and engineers used AutoCAD mainly for design, drawing and presentation purposes, quantity surveyors use it mainly for measurement purposes, preparation of bills of quantities, estimating and for presentation purposes as well. The engineering analysis software for specific branches of engineering includes Microstran, and MathCAD (Doherty, 1997). In model structural design software, software's with 3D, 4D and even 5D modeling capacities, designing complex structures is now facilitated where previously this was almost impossible to achieve (Walker, Hampson \& Ashton, 2003). Furthermore quantity surveying softwares such as WinQS, QS Plus2001, Candy, QsCAD and Masterbill among others (Murray, Nkado \& Lai, 2001) speed up the process of taking off and working up but also enhance the accuracy of quantity surveying functions from approximate estimating to final accounts of a project. A detailed description of many of the available software for architects, engineers and quantity surveyors is thoroughly outlined in Murray, Nkado \& Lai (2001).

In addition to these application of ICT to what may be termed the traditional domains of architectural, engineering and quantity surveying professions, there are some ideas that have emerged in area of ICT 
innovations and applications. These innovations include knowledge management (KM), electronic document management (EDM) and e-business. ICT facilitates the transfer of knowledge and information between project teams, enabling the development of new knowledge for innovation (Gann, 2000). The recent developments of EDM systems for project management can save a considerable amount of time and cost with regards to document transfer and information exchange among project participants in the industry, while on the other hand e-business provides an efficient infrastructure for remote consulting services to consultants who desire to provide their professional services to clients in need of their services through internet, and email requests. Professionals within the South Africa construction industry must learn to avail themselves to the various tools provided through ICT to improve the quality and speed of their work in the project chain, from project inception to testing and commissioning. Given the rapid rate of fall in the prices of ICT hardware and software globally and the tremendous benefits ICT offers, it should not be too expensive for construction professionals in South Africa and other developing countries to embrace the technology. Perhaps the critical requirement now (Murray, Nkado\& Lai, 2001)is the need for investment in ICT education to students in varsity so as to prepare them for the corporate world and easy adjustment to the world of work and quick accese to being professionals by the time they graduate.

\section{Methodology}

This section presents an explanation of the methodology used in conducting the research. A cross sectional, systematic random questionnaire survey was used to determine the views of consulting professionals on the impact of ICT on their practices in the South African construction industry around the Johannesburg region. This was in line with Cooper and Schindler (2006) position on the concept of random selection being a controlled procedure that assures that each population element is given a known non-zero or allows each member of the population to have an equal chance of being selected. The questionnaire survey was conducted amongst 60 construction professionals. The questionnaires were distributed personally by the researcher to various construction organizations around the Johannesburg region. The questionnaires were tailored to consulting professionals only. The exploratory phase sample frame consisted of the various construction organizations randomly selected from Johannesburg region. These include: Civil engineering consultants, architectural practices, contracts managers, construction managers, project managers and quantity surveyors. Subjects for the study were drawn from various construction organizations in Johannesburg region. The participants were located in different areas as they were selected randomly; some were located in South of Johannesburg, others in North of Johannesburg while others were in Johannesburg CBD. The selected respondents participated in the study on a voluntarily basis and did not have to sign consent for. The details of those participants who partook in the study will remain anonymous, in order to prevent possible discrimination by the employer. The selection of a sample of this nature was based on the justification by Smith (2004) who informed that random sampling must be used for a study of this nature, hence it was adopted. Also, according to Neuman (2006), the question of how large a sample should be, depends on the following: the kind of data analysis the researcher plans to use; how accurate the sample has to be for the researcher's purposes and the population characteristics.

Likewise, Malhotra (1999) informs that the determination of sample size depends on factors, such as the proposed data analysis techniques, financial and access to sampling frame. Neuman (2006) informs that a large sample size alone does not guarantee a representative sample. This is because a large sample size without random sampling (as used in the present study) or with a poor sampling frame is less representative than a smaller one with random sampling and an excellent sampling frame. Although, the larger the size of the sample, the more likely its mean and standard deviation will be representative of the population's mean and standard deviation. Owing to limitations imposed by time, only 37 were collected back as most professional were busy with one endeavour or the other. This reprsented a response rate of $62.0 \%$. This was considered adequate for the study analysis based on the assertion by Moser and Kalton (1971) that the result of a survey could be considered as biased and of little value if the return rate is lower than $30-40 \%$. The data presentation and analysis made use of frequency distributions and percentages of all the respondents. The research was conducted between the months in the month of July to August, 2012.

Relative significance index (RSI): A 5-point Likert type scale was used to determine the response times and risks associated with the usage of ICT in the South African construction industry professional practises with regards to the identified factors from the reviewed literature. The adopted scale read as follows, 1 =strongly disagree, 2=Disagree, $3=$ Neutral, 4=Agree, and strongly agree. The 5-point Likert scale 
was transformed to a relative significance index for each of the factors of response times as assessed by the respondents. The indices were then used to determine the rank of each item. These rankings made it possible to cross compare the relative significance of the items as perceived by the respondents to impact the various aspects of the study, because it is necessary to highlight the relative significance of the factors (Lim and Alum, 1995). The Relative significance index was used for ranking of the factors. This method has been used in construction research (Lim and Alum, 1995).The RSI is a non-parametric technique based on the aggregate weighting of the initial frequency score of each factor (Lim and Alum, 1995).The computation of the relative significance indices (RSI) was calculated from the total of all weighted responses and then relating it to the total responses on a particular aspect. This was based on the principle that respondents' scores on all the selected criteria, considered together, are the empirically determined indices of relative importance. The index of RSI of a particular factor is the sum of respondents' actual scores (on the 5-point Likert scale) given by all respondents' as a proportion of the sum of all maximum possible scores on the 5-point Likert scale that all the respondents could give to the criterion. Weighting were assigned to each responses ranging from one being strongly disagree with the statement to five being in total agreement with the statement posed to the respondents. The relative significance index (RSI) was calculated for each item as follows, after Lim and Alum (1995).

$\begin{array}{lll} & = & \underline{1 \alpha_{1}+2 \alpha_{2}+3 \alpha_{3} \underline{+4 \alpha_{4}} \underline{+5} \alpha_{5}} \\ \text { Where; } & & \\ \alpha_{1} & = & \text { number of respondents for strongly disagree. } \\ \alpha_{5} & = & \text { number of respondents for strongly agree. } \\ \sum \alpha & = & \text { Total number of respondents }\end{array}$

Following the mathematical computations, the criteria are taken ranked in descending order of their relative significant index (from the highest to the lowest). The next section of the study presents the findings of the survey and some discussions as well.

\section{Findings and Discussion}

Findings from the 37 usable questionnaires revealed that $59 \%$ of the respondents were male, while $41 \%$ were females; suggesting that the construction industry is still a male dominated industry. Further findings revealed that $59 \%$ of the respondents have a B-degree or its equivalent. Also, findings showed that $41 \%$ of the respondents were between the ages of $31-35$ years of age; with an average of $6-10$ years' experience in the industry. Also, findings revealed that $40 \%$ of the respondents indicated that they are working for large construction consulting firm; while a $60 \%$ are working for a combination of small to medium construction consulting firms. Hence, when respondents were assessed on the drive to adopted ICT in running of their business affairs. Findings as shown in Table 1 revealed that changing trends in the global construction industry is the most significance factor driving professional consulting firms to adopt the use of ICT with an RSI=3.57. This was followed by client/customer demand (RSI=3.41); construction industry demands (RSI=3.32) and competition being the least factor. This suggests that increasing marketization of the South African economy and the construction industry sector is compelling firms to adjust themselves to the changing trends in technology as previous research findings has shown (Peansupap \& Walker, 2005).

Table 1: Factors determine use of ICT

\begin{tabular}{lll}
\hline Factors & R.S.I & Rank \\
\hline Changing trends in the global construction industry & 3.57 & 1 \\
Client/customer demand & 3.41 & 2 \\
Construction industry demands & 3.32 & 3 \\
Level of competition & 3.35 & 4 \\
\hline
\end{tabular}

Furthermore, when the respondents were asked about the constraints faced in the use of ICT in their consulting firms, Table 2 summarise the findings of the constraints. Based on the ranking (R) of the weighted average of the RSI, it was found that the most dominant factor with regards to constraints of using ICT systems in the South African construction industry consulting firms were continual need to upgrade (RSI=4.16; $R=1$ ), personal abuse and high cost ( $R S I=3.76 ; R=2)$, poor security and privacy and high cost or professional to employ (RSI=3.73; $\mathrm{R}=3$ ), system and computer malfunction and virus attacks $(\mathrm{RSI}=3.69 ; \mathrm{R}=4)$. Other factors assessed which were not considered as major constraints to the adaptation 
and use of ICT in the South African professional practise firms include; poor return on investment ( $\mathrm{RSI}=3.49 ; \mathrm{R}=8$ ), inadequate power supply $(\mathrm{RSI}=3.43$; $\mathrm{R}=9$ ), and ICT making professional redundant (RSI=3.38; R=10).

Table 2: Constraints to the use of ICT by the consultants

\begin{tabular}{lll}
\hline Constraints & R.S.I & Rank \\
\hline Continual need to upgrade & 4.16 & 1 \\
Personal abuse & 3.76 & 2 \\
High Cost & 3.76 & 2 \\
Poor security and privacy & 3.73 & 3 \\
High cost or professional to employ & 3.73 & 3 \\
System and computer malfunction and virus attacks & 3.69 & 4 \\
Incompatibility in software packages & 3.63 & 5 \\
Inefficiency from ICT & 3.54 & 6 \\
Incompatibility in software packages & 3.58 & 7 \\
Poor return on investment & 3.49 & 8 \\
Inadequate power supply & 3.43 & 9 \\
ICT making professional redundant & 3.38 & 10 \\
\hline
\end{tabular}

Furthermore, in order to meet the study objective three, the respondents were asked to score the most evident benefit the adaptation and use of ICT has brought to their professional consultancy services. Table 3 below summarise the findings.

Table 3: benefits of ICT usage to the consultants

\begin{tabular}{lll}
\hline Benefit & R.S.I & Rank \\
\hline Time saving & 4.41 & 1 \\
Ease of doing complex tasks & 4.16 & 2 \\
Increases Productivity & 4.16 & 2 \\
Increase speed of work & 4.16 & 2 \\
Increases document quality & 4.14 & 3 \\
Speeds up response times & 4.03 & 4 \\
Reduces mistakes in document & 3.97 & 5 \\
Reduces degree of difficulty & 3.95 & 6 \\
Ease of doing complex tasks & 3.95 & 6 \\
Reduces proportion of new work & 3.92 & 7 \\
Reduces mistakes in document & 3.86 & 8 \\
Reduces construction error & 3.81 & 9 \\
\hline
\end{tabular}

The findings revealed that the most dominant factor with regards to benefits of using ICT systems in the South African construction industry professional firms were time saving (RSI=4.41; $\mathrm{R}=1$ ), ease of doing complex tasks, increases productivity which increases speed of work, all having the same score ( $R S I=4.16 ; \mathrm{R}=2$ ); increases document quality ( $\mathrm{RSI}=4.14 ; \mathrm{R}=3$ ), speeds up response times $(\mathrm{RSI}=4.03 ; \mathrm{R}=4$ ). Other factors include; Reduces proportion of new work (RSI=3.92; $\mathrm{R}=7$ ), reduces mistakes in document (RSI=3.86; $\mathrm{R}=8$ ) and reduces construction error (RSI=3.81; $\mathrm{R}=9$ ).Findings from the survey reveal the typical constraints faced by construction professional firm in the adaption and usage of ICT, as they need to stay updated with the ever changing ICT software. Also, the aspect of personal abuse of the ICT and high cost are correlated as abuse of ICT systems from employees' leads to high cost in the maintenance of the systems in place. However, the respondents do not see inadequate power supply as a constraints to the use of ICT systems as constant electricity power supply is not a problem in South Africa, but it does add to the high cost of running ICT systems. Likewise the respondents do not agree that ICT makes professional redundant, suggesting that when ICT is properly utilized, it makes professionals to better 
respond to the need of their clients. This finding concurs with the work of Walker, Hampson \& Ashton (2003) who states that with availability of 3D modelling software for example, complex designs which were previously almost impossible to design are now being designed with ease. The finding that ICT improves communication and response times within the construction industry to enhance decision making also agrees with the work of Peansupap \& Walker (2005)and Ozumba and Shankatu (2009), which also indicates that proper ICT usage ultimately yields time and cost savings. Time and cost are not the only aspect of savings, but the nine bodies of knowledge under project management are utilized to their full extent as ICT comes in as a catalyst to improve what is already there. This aspect include: scope of work is easily handled with ICT usage; quality is achieved with better accuracy; risk is minimised by using ICT systems; time is saved on repetitive work; human resource management is adequately utilized; procurement is done much more efficiency; cost is reduced and kept at a minimum; communication is achieved much more effectively and better integration that forms a collaborative working environment amongst professionals. However, the professional does not see ICT and it adaptation in the reduction of mistakes in the execution of their everyday duties, likewise, the reduction of construction of errors.

The findings disagreed with the works of Davenport (1993), Odedra-Straub (1996) and Chinn \& Fairlie (2004), which informs that developing countries still have low computer penetration rates. But it should be re-stated as found that the adoption of ICT is in response to the changing trends in technology in the construction industry. From the researcher's personal search of the surveyed firms, it was observed that almost two-third of the firms surveyed are connected to the Internet, which they use mainly for e-mail communication (strategic use of the internet). Such strategic uses of the Internet as electronic data transfer and e-business are virtually unheard of; but it has become the trend of the modern day professional practice. Furthermore, findings highlight the wide gap in ICT infrastructure which, according to Chinn \& Farlie (2004) and Ozumba and Shankatu (2009) exists between developed and developing countries. In spite of these problems, a majority of the respondents were optimistic about the increased use of ICT in their practices in future, with major new investments planned for such application as teleworking, BIM (Building Information Modelling) and electronic data management (EDM).

\section{Conclusion}

The study was carried out to assess the impact ICT has had on architectural, engineering, project management and quantity surveying practices, which are the main producers and managers of project information, in the South African construction industry. The results of the structured questionnaire survey of firms in these practices were presented in this paper. The results indicated a high level of computerisation of professional services. Also, findings revealed that the diffusion of ICT in the construction industry is greatly hampered by such factors as continual need to upgrade ICT software and hardware, personal abuse, high cost and poor security and privacy. The fact that the problem of continual need to upgrade is the most prominent obstacle in this study and does feature in most of the similar studies in industrialised and newly industrialised economies makes it peculiar to a developing country like South Africa. Although, software upgrading is necessary because better versions of the programme are being released which enhances work. While existing reports on the use of ICT in the construction industries of developed countries such as New Zealand, Canada, Sweden and Singapore indicate that the high rate of obsolescence of hardware and software is the most prominent obstacle to use of ICT, it was established in this study that for South African, the cost of electricity supply is not a significant factor in the adaptation of ICT. In summary, the study has x-rayed the state of ICT in professional practices in the South African construction industry and has attempted to show that the most critical challenges facing construction professionals in the use of ICT are quite different for developed countries and developing countries like South Africa. It is therefore recommended that the South Africa Construction Industry should endeavour to fully adapt to appropriate ICT innovations for its construction industry practicing forms, which is one of the most strategic industries in the nation's development agenda. Hence, as ICT gains more adaptation usage, the benefit will be reaped through employment provision to the unemployed in the country.

\section{References}

Chalkey, R. (1990). Professional conducts: A Handbook for Chartered Surveyors. Surveyors Holdings Ltd, London.

Chinn, M. D. \& Fairlie, R. W. (2004). The Determinants of the Global Digital Divide: A cross-country analysis of computer and internet penetration, Center for Global, International and Regional 
Studies, Working Paper Series qt6hz053p3, Center for Global, International and Regional Studies, UC Santa Cruz.

Construction Industry Development Board. (2005). Best Practice Guideline \#A7. The procurement of professional services. Construction Industry Development Board: Pretoria

Cooper, D. \& Schindler, P. (2006). Marketing Research. New York: McGraw-Hill.

Davenport, T. (1993). Process Innovation: Reengineering Work through Information Technology. Boston: Harvard Business School Press.

Doherty, J. (1997). A Survey of Computer Use in the New Zealand Building and Construction Industry. Journal of Information Technology in Construction, 2(1), 73-86.

Gann, D. (2000). Building Innovation: Complex Constructs in a Changing World. 1 ed. London: Thomas Telford

Goh, B. (2005). IT Barometer: Survey of the Singapore Construction Industry and a Comparison of Results. Journal of Information Technology in Construction, 10(1), 1-13.

Lim, E. C. \& Alum, J. (1995). Construction productivity: issues encountered by contractors in Singapore. International Journal of Project Management, 13(1), 51-8.

Liston, K., Fischer, M. \& Kunz, J. (2000). Designing and Evaluating Visualization Techniques for Construction Planning. Computing in Civil and Building Engineering, (2), 1293-1300.

Malhotra, N. K. (1999). Marketing research: An applied orientation. 3rd edn. New Jersey: Prentice Hall.

Moser, C. A. \& Kalton, G. (1971). Survey methods in social investigation. UK, Heinemann Educational.

Murray, M., Nkado, R. \& Lai, A. (2001). The Integrated Use of Information Technology in the construction Industry. Proc. of CIB 78 Conference: IT in Construction in Africa, 39(1), 13-39.

Neuman, W. L. (2006). Social research methods qualitative and quantitative Approaches. 6th edn. Boston: Pearson.

Oladapo, A. A. (2006). Impact of ICT on Professional Practice in the Nigerian Construction Industry. The Eletronic Journal on Information Systems in Developing Countires, 24(2), 1-19.

Odedra-Straub, M. (1996). Global Information Technology and Socio-economic Development. 1st ed. Nashua: Ivy League Publishing.

Ozumba, O. \& Shankatu, W. (2009). Balancing site information and communication technology systems with available ICT skills, RICS COBRA Research Conference. Cape Town, University of Cape Town.

Peansupap, V. \& Walker, D. (2005). Factors affecting ICT diffusion: A case study of three large Australian construction contractors. Engineering, Construction and Architectural Management, 12(1), 21-37.

Rivard, H., Froese, T., Waugh, L. M., El-Diraby, T., Mora, R., Torres, H., Gill, S. M. \& O'Reilly, T. (2004). Case Studies on the Use of Information Technology in the Canadian Construction Industry. Journal of Information Technology in Construction, 9(1), 19-34.

Segalas, J., Ferrer-Balas, D. \& Mulder, K. F. (2010). What do engineering students learn in sustainability courses? The effect of the pedagogical approach. J. Cleaner Prod., 18(3), 275-284.

Smith, M. H. (2004). A Sample/Population size activity: Is it the sample size of the sample as a fraction of the population that matters? Journal of statistics education, 12(2), 1-12.

Ruikar, K., Anumba, C. J. \& Carrillo, P. M. (2005). End-user perspectives on use of project extranets in construction organizations. Engineering, Construction and Architectural Management, 12(3), 222 $-235$

Shoesmith, D. (1995). Using Internet as a Dissemination Channel for Construction Research. Construction Information Technology, 3(2), 65-75.

The Association of Professional Engineers and Geoscientists of Alberta. (2013). Guideline for Professional Practice v1.2. Edmonton, Alberta

Toole, T. (2003). Information Technology Innovation: A View of Large Contractors. Honolulu, Proc. of the ASCE Construction Research Congress.

Vee, C. \& Skitmore, M. (2003). Professional Ethics in the Construction Industry. Eng. Constr. Archit. Manage., 10(2), 117-127.

Walker, D., Hampson, K. \& Ashton, S. (2003). Developing an innovative culture through relationship-based procurement systems. In: Walker, D and Hampson, K (Ed.), Procurement strategies. UK: Blackwell. 